\title{
IMPACT OF THE ENVIRONMENTAL FACTORS AND its EFFECTS ON ProduCTIVITY AND HeALTH
}

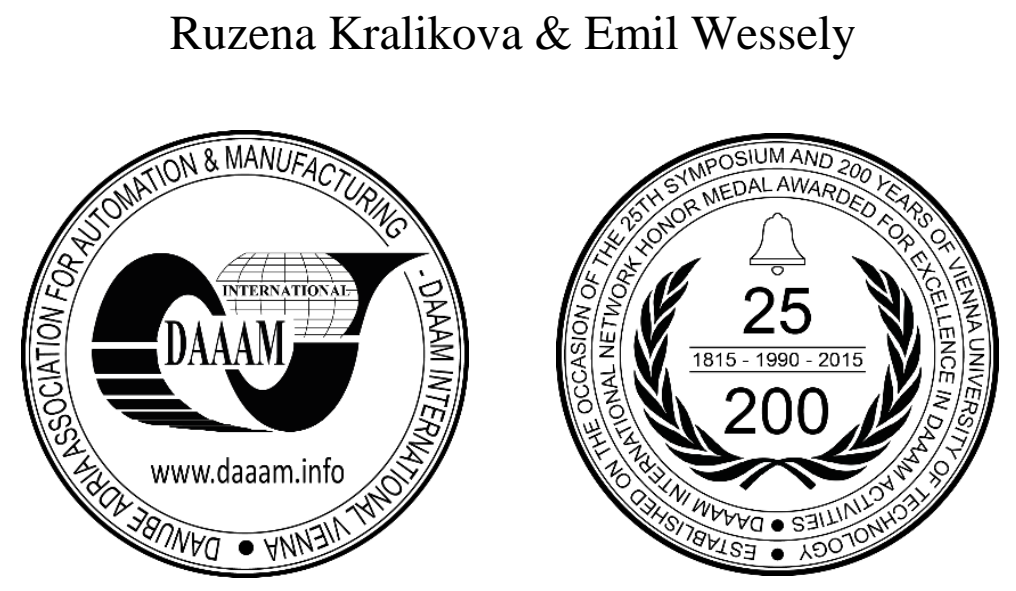

This Publication has to be referred as: Kralikova, R[uzena] \& Wessely, E[mil] (2018). Impact of the Environmental Factors and its Effects on Productivity and Health, Proceedings of the 29th DAAAM International Symposium, pp.0119-0124, B. Katalinic (Ed.), Published by DAAAM International, ISBN 978-3-902734-20-4, ISSN 1726-9679, Vienna, Austria

DOI: $10.2507 / 29$ th.daaam.proceedings.016

\begin{abstract}
The objective of this study was to determine the dominance impacts of environmental factors such as illuminance (lx), operative temperature $\left({ }^{\circ} \mathrm{C}\right)$, relative humidity $(\%)$, air flow velocity $\left(\mathrm{m} . \mathrm{s}^{-1}\right)$ on the operators' productivity at mechanical engineering industry. The subject were workers of the workstation space at the assembly section of the factory. Two sets of representative data level and production rate were collected by objective and subjective methods. All monitored factors were measured using calibrated multifunction apparatus which is capable to measure those mentioned environmental factors simultaneously. The obtained data from questionary survey realized in the same factory were statistical calculates with goal to identify the most significant factors from point of productivity view. Then was being utilized to find the sequence of dominance factors that contributed to the productivity of operator at the specified production workstation.
\end{abstract}

Keywords: illuminance; temperature; humidity; air flow velocity productivity; questionnaire survey

\section{Introduction}

In a production plant, information about productivity is an important indicator of performance. Improving workers' productivity, occupational health and safety are major concerns of industry. Noise, air quality, light and the thermal environment are considered factors that would influence the acceptability and performance on the occupants of premises [11]. Irritated, sore eyes and throat, hoarseness, stuffy congested nose, excessive mental fatigue, headache and unusual tiredness are all signs of the negative workplace environmental conditions.

Temperature effects on labour productivity are well documented. High and low temperatures not only cause physical discomfort and fatigue but can also affect cognitive functioning. Existing studies have documented these biological effects [17], [18]. Employees with complaints of discomfort and dissatisfaction at work could have their productivity affected, result of their inability to perform their work properly [15], [16]. It should be noted that optimal performance (productivity) does not necessarily occur under optimal thermal comfort conditions, because the productivity is strongly dependent on the nature of the performed task [2]. 
Also, lighting is a very important factor in the working environment that directly affects performance and productivity. The visual system is directly linked to the central nervous system and the fatigue of the eyes always affect in the overall psychological state of the organism. Lighting has an impact on satisfaction, health, accident, etc. The relationship between the change of lighting and the productivity of work has confirmed some research. Viteles gives an example that, in the laundry was increased lighting by $70 \mathrm{~lx}$, performance after this change increased by 17\% [23]. But the effect of lighting on productivity is ambiguous. The difficulty in finding the relations between lighting and productivity is that there are several other factors that simultaneously affect human performance [1]. These factors include motivation, relationships between workers and the management and the degree of having personal control to the working conditions [3], [5], [7].

\section{Linkage between productivity and temperature}

The feeling of comfort and awareness of the environmental conditions are associated with metabolic heat production and the ensuing adjustments of body temperature. for determining a comfort zone and defining limits, comfort zone according to ISO, comfort zone according to ASHRAE, and the concept of Heat Index. The standard ISO 7730:2005 is an approach used in Europe for defining the comfort zone, Fig.1.

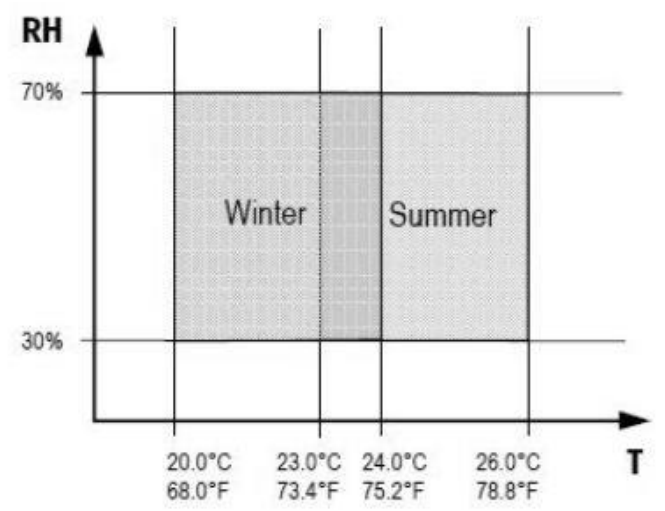

Fig. 1. RH/T diagram showing the comfort zone according to ISO 7730

\subsection{Thermal Comfort}

Humans have been creating spaces to induce thermal comfort for eons. The long-established components of comfort include air temperature, mean radiant temperature, humidity, and air velocity within the space, along with the personal factors of clothing insulation and activity level. But understanding of what makes a space comfortable is still evolving, and these components, we're discovering, represent only part of the puzzle of thermal comfort [4].

The most common definition of a „comfort zone“ or range of environments which are experienced as comfortable is based on the American Society of Heating, Refrigerating and Air-Conditioning Engineers (ASHRAE standard 55) seven-point scale of comfort [9]. Thermal comfort can be measured as the predicted mean vote (PMV), which is a scale from -3 (cold) to +3 (hot) (Table 1). The value is derived from a complex equation that factors in a range of criteria, including clothing insulation, metabolic rate, air velocity, vapour pressure, and the mean radiant temperature (MRT). Generally, thermal comfort guidelines recommend that interior spaces be regulated such that the PMV is between - 0.5 and +0.5 .

\begin{tabular}{|c|c|}
\hline Value & Sensation \\
\hline+3 & Hot \\
\hline+2 & Warm \\
\hline+1 & Slightly warm \\
\hline 0 & Neutral \\
\hline-1 & Slightly cool \\
\hline-2 & Cool \\
\hline-3 & Cold \\
\hline
\end{tabular}

Table 1. The predicted mean vote (PMV) scale for measuring thermal comfort

The PMV can be used to calculate the predicted percentage dissatisfied (PPD). The PPD is a function of the PMV, and describes the expected percentage of people dissatisfied with their thermal environment given the PMV. As the PMV moves away from 0 , the PPD increases. 
$100 \%$ PPD would indicate that $100 \%$ of people would be expected to be dissatisfied with the thermal environment. Therefore, guidelines suggest that interior spaces should aim for a PPD below $10 \%$. Below are ways to ensure that through good design, construction and maintenance, you can keep PMV within a narrow range around zero, and thus minimise the PPD.

\section{The effect of lighting on productivity}

Lighting should be designed to provide people with the right visual conditions that help them to perform visual tasks efficiently, safely and comfortably. The luminous environment acts through a chain of mechanisms on human physiological and psychological factors, which further influence human performance and productivity [6], [12]. With appropriate lighting the ability to perform visual tasks can be improved and visual discomfort can be avoided. This can provide conditions for better visual and task performance and, ultimately, productivity.

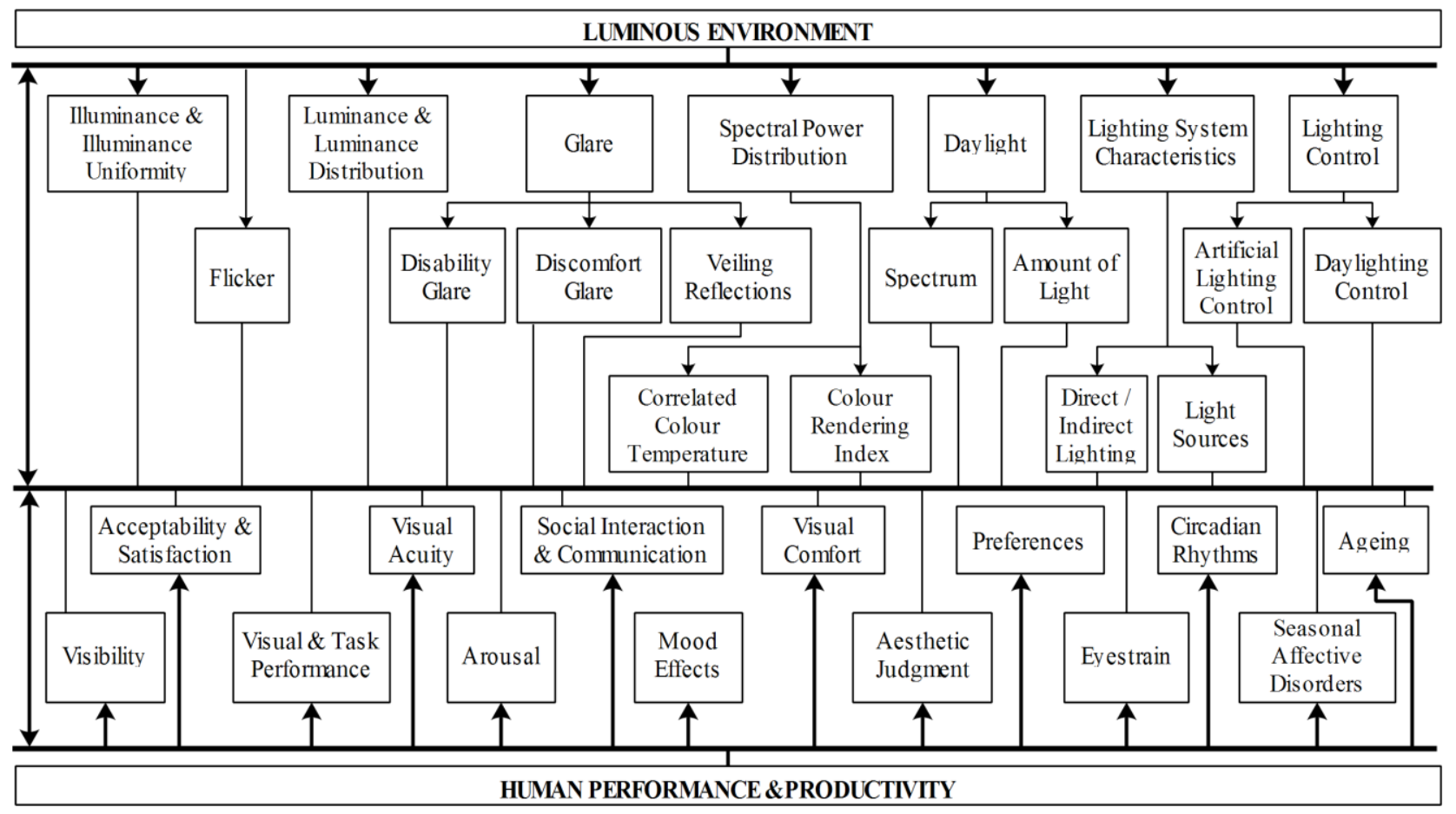

Fig. 2. Luminous environment and human performance [13]

The difficulty of field studies in working environments is the degree of experimental control required. Several studies have investigated the effect of increase in illuminance on task performance. However, illuminance is only one of the many aspects in the lighting conditions. In making changes to lighting, which lighting aspects are changed (e.g. illuminance, spectrum, and luminance distribution) and whether there are other factors that are simultaneously changed in the working conditions (e.g. working arrangements, people, supervision of work) need to be controlled and analysed .

Recently, several studies are investigating the effects of light spectrum on human performance and the possibilities to use blue-enriched light to improve human performance through the non-visual effects of light. Poor lighting conditions can easily result in losses in productivity of employees and the resulting production costs of the employer can be much higher than the annual ownership cost of lighting. The effects on performance are not yet very well known. Lighting should be designed to provide people with the right visual conditions that help them to perform visual tasks efficiently, safely and comfortably [6]. The luminous environment acts through a chain of mechanisms on human physiological and psychological factors, which further influence human performance and productivity, Fig. 2.

\section{Research Methodology}

Evaluation and assessing the microclimate and illuminance of the working environment requires a comparison of the identified facts with the requirements of the standards and the applicable regulations.

There are two basic approaches to assessing the work environment:

- Objective assessment of measurable factors, using current measurement methods [19], [20], [21], [22].

- Subjective assessment under which measures are taken to improve the current situation; frequently a questionnaire survey or a structured interview technique is used. 


\subsection{Objective method}

Objective evaluation methods microclimate conditions consist in comparing the measured values with the limit values laid down under the heat balance equation. A prerequisite of a person's thermal balance is the need to guide the temperature of man's production and the transmission properties of his garment. Heat production of man depends on the mechanical work performed, the transmission properties of the garment are characterized by the thermal resistance of the garment. The standard values are given taking into account the annual period and the individual working categories in the Annex to Slovak degree no. 99/2016 Coll. and norm ISO 7730:2005. The standard values of illuminance on place and overall average lighting are given in Annex to Slovak degree no. 541/2007 Coll. and norm EN 12 464-1.

The measurement was carried out in the workshop of the engineering organization located in a one-storey hall building during a warm day. Warm period of the year is stated as period during which average daily outdoor air temperature is $13^{\circ} \mathrm{C}$ or higher. Daily temperatures ranged from $+30^{\circ} \mathrm{C}$ up to $+35^{\circ} \mathrm{C}$, with relative humidity ranged from $45 \%$ to $56 \%$ and air velocity $v_{a}$ from $2.27 \mathrm{~ms}^{-1}$ to $6.25 \mathrm{~ms}^{-1}$. Parameters characterizing the work activities performed at the workshop workplace are given in Table 2.

\begin{tabular}{|c|c|}
\hline Characteristics of work & Middle assembly of small light parts \\
\hline Specification & $\begin{array}{c}\text { The stand-up work, slow walk on a flat floor with the } \\
\text { carrying of light loads or overcoming a small resistance }\end{array}$ \\
\hline Job Class & $2 \mathrm{a}$ \\
\hline Heat resistance of clothing & Rcl $=0,64$ clo \\
\hline Metabolic rate & $131-160 \mathrm{~W} \cdot \mathrm{m}^{-2}$ \\
\hline Exposure of workers & 8 hours per shift \\
\hline
\end{tabular}

Table 2. Parameters characterizing the work activities

Also, the aim of the research was to compare the results objectivized by the measurement with values determined by directives and normative, see Table 3.

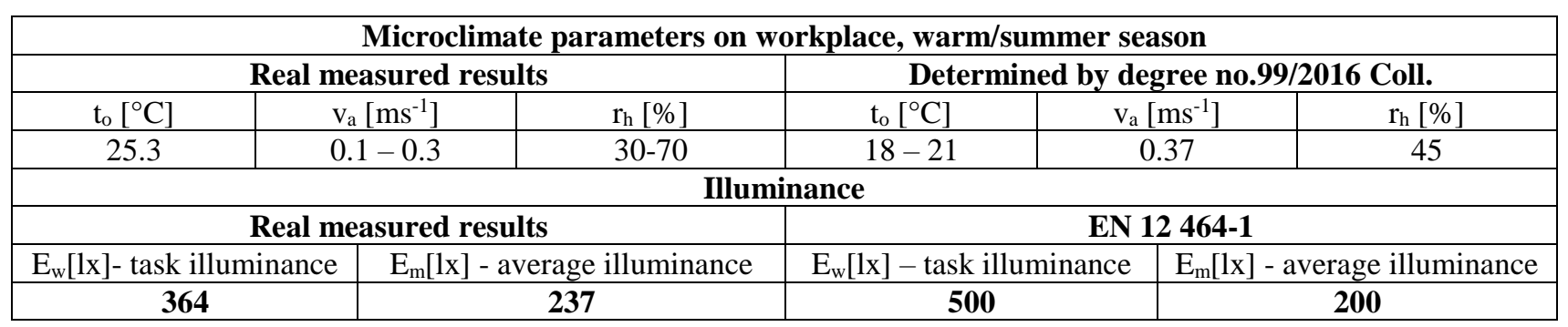

Table 3. Microclimate and lighting parameters [21], [22]

In the next step, we explore the manner in which the various environmental parameters affect the perceived productivity according to results of questionnaire survey.

\subsection{Subjective evaluation of the self-assessed productivity}

Subjective evaluation was conducted in the form of a structured questionnaire. In this research was explores the selfassessed productivity to the objective environment according to the effect of visual and thermal conditions in working process. The representation of workers (men/women) at the 5 work section (assembly lines) is shown in the following Table 4.

\begin{tabular}{|l|c|c|c|c|c|c|}
\cline { 2 - 7 } \multicolumn{1}{c|}{} & Line 1 & Line 2 & Line 3 & Line 4 & Line 5 & sum \\
\hline Male & 29 & 35 & 28 & 15 & 16 & $123(64 \%)$ \\
\hline Female & 5 & 5 & 10 & 25 & 24 & $69(36 \%)$ \\
\hline Total & 34 & 40 & 38 & 40 & 40 & $192(100 \%)$ \\
\hline
\end{tabular}

Table 4. Representation of respondents in the work sections

The dependences of perceived productivity on the environmental variables were assessed according to the results of the subjective evaluation obtained by the questionnaire survey. The survey sample was made up of employees who met all of our conditions. The sample set was 192 employees (respondents) from manufacturing organizations aged 23-60. The average age of respondents who participated in the research was approximately 33 years. $123(64 \%)$ men and 69 (36\%) women were surveyed. In the age category up to 24 years old there were 71 respondents $(35.5 \%), 65$ respondents (33.5\%) were aged 25-34 years old. In the age group 35-44 there were 44 respondents (24\%) and 12 respondents (7\%) were aged 45 and over. 


\section{Test of dependence between productivity and environmental factors}

In next research we will to analyse of the variance of monitored parameters further. We could explore the manner in which the various environmental parameters affected the perceived productivity to a significant extent and than to explore the form of their effect- whether there were an optimum value of the factors complied with normatives and how are the monitored parameters statistically significant. The desire to evaluate the effects of the environmental factors on the self-assessed productivity were used the scale of self-assessment, Tab. 5. The response indicated the extent to which, in the opinion of the respondent, the quality of their environmental factors were helping or hindering their work. This response is termed the "perceived productivity ". The perceived effect as rarely/neutral was the most frequented answer.

\begin{tabular}{|l|c|c|c|c|c|}
\cline { 2 - 6 } \multicolumn{1}{c|}{} & \multicolumn{5}{c|}{ Environmental Factors } \\
\hline Frequency & B1- temperature & B2 - humidity & B3 - air velocity & B4 - task lighting & B5 - average illuminance \\
\hline Never & $10(5.2 \%)$ & $27(14.1 \%)$ & $25(13.1 \%)$ & $7(3.6 \%)$ & $123(64.1 \%)$ \\
\hline Rarely/Neutral & $96(50.0 \%)$ & $115(59.9 \%)$ & $102(53.1 \%)$ & $94(49.0 \%)$ & $64(33.3 \%)$ \\
\hline Often & $74(38.5 \%)$ & $46(23.9 \%)$ & $55(28.6 \%)$ & $75(39.1 \%)$ & $5(2.6 \%)$ \\
\hline Very often & $12(6.3 \%)$ & $4(2.1 \%)$ & $10(5.2 \%)$ & $16(8.3 \%)$ & - \\
\hline Average rating & $\mathbf{2 . 5}$ & $\mathbf{2 . 1}$ & $\mathbf{2 . 3}$ & $\mathbf{2 . 5}$ & $\mathbf{1 . 4}$ \\
\hline
\end{tabular}

Explanatory notes:

B1 - effect of temperature on self-assessed productivity, B2 - effect of relative humidity on self-assessed productivity,

B3 - effect of air velocity on self-assessed productivity, B4 - effect of task illuminance on self-assessed productivity,

B5 - effect of average indoor illuminance on self-assessed productivity.

Table 5. Dependence of perceived productivity on the environmental conditions

Respondents subjectively evaluated the microclimatic and illuminance conditions and productivity problems on an evaluation scale as follows: "never $=1$ ", "occasionally / rarely =2", "often = 3", "very often / almost always =4" (see Table 5.). The average score of the thermal and illuminance sensation corresponding to perceived productivity was 2.15. The intrinsic consistency (reliability) of the subjective assessments was determined by the Cronbach's alpha coefficient. The value of 0.9 indicates very good reliability. To determine the interdependence between selected category symbols, Pearson's chi-squared test was used. The assessment of the closeness of the determined dependence between the category characters was performed using the contingency coefficient $\Phi$. Relationships between selected items of subjective evaluation were also expressed using the Pearson correlation coefficient [8], [14], Table 6.

\begin{tabular}{|c|c|c|c|c|c|}
\hline & B1- temperature & B2 - humidity & B3 - air velocity & B4 - task light & B5 - aver. light \\
\hline Chi $^{2}$-test & 7,95 & 9,48 & 10,37 & 15,8 & 1,98 \\
\hline p-value & 0,047 & 0,15 & 0,03 & 0,001 & 0,37 \\
\hline$\Phi$ & 0,20 & - & 0,23 & 0,29 & - \\
\hline
\end{tabular}

Table 6. Pearson's chi-squared test results

The Table 6 shows results of the Pearson's chi-squared test. The greatest effect on perceived productivity had illuminance of working place and it was highly significant statistically $(\mathrm{p}=0.001)$. The temperature had a smaller but statistically significant effect $(\mathrm{p}=0.047)$. The air flow velocity had a smaller but statistically significant effect $(\mathrm{p}=0.031)$. The effects of humidity and average maintenance illumination did not approach statistically significance. This leads to the conclusion that, for the ranges of variables counted in the questionary survey, only the task illuminance had a reliable effect on the perceived productivity [10].

\section{Conclusion}

Based on workers' responses to the number of questions, we can suppose that improving productivity can lead to more energy consumption in lighting or heating for improving the indoor environment, which could have significant energy and cost implications. One of the potential short-term or long-term responses for employers is the implementation of measures such as lighting and heating innovation by the implementaion of light control and HVAC systems, regardless of energy or investment implications.

It should be noted that optimal performance (productivity) does not necessarily occur under optimal environmental conditions, because the productivity is strongly dependent on the nature of the performed task, too. The next goals of the future research will to the specify of the level perceived productivity and to explore the effect of environmental parameters - to find an optimum level of the environmental variables depending on the type of performed task for the productivity increase reason. 
Today's competitive environment requires not only competitive technological equipment and efficient, cheaper and more stable processes, but also an emphasis on the third pillar of the production process, i.e. the workers themselves. Experienced and highly satisfied worker (the knowledge worker) once again plays an important role in business process management, and businesses must try to ensure that "well-trained and trained workers" do not leave the job. More important role of employer is played by the above-mentioned employee satisfaction and their impact on labour productivity. This is why not only in many companies they are increasingly focusing on improving working conditions. Suitable conditions at the workplace "living conditions" are essential for production. As the most important source of entrepreneurship, today still in high automation, at the threshold of the so-called 4th Industrial revolution.

\section{Acknowledgments}

The research in this paper was supported by national grants: KEGA No 045 TUKE-4/2018 "Transfer of the latest findings of research into processing textbook" (50\%) and KEGA No 032 TUKE-4/2018 "Intensification of education and Information processes in engineering for quality of the environment" (50\%) supported by Slovak Research.

\section{References}

[1] Boyce, P. R. (2004). Lighting research for interiors: the beginning of the end or the end of the beginning. In: Lighting Research and Technology.Vol.36,No.4, pp.283-293.

[2] Brager, G.S. ; Zhang, H. \& Arens, E., (2015): Evolving opportunities for providing thermal comfort. Building Research \&Information,43(3), 274-287.

[3] d'Ambrosio Alfano F.R.; Palalla, B.I. \& Riccio, G. (2011) Thermal Environment Assessment Reliability Using Temperature-Humidity Indices, in: Industrial health, 49, pp. 95-106. ISSN: 0019-8366.

[4] Fanger, P.O. (1970). Thermal Comfort. Danish Technical Press, Copenhagen. ISBN 0-07-019915-9, pp.21-27.

[5] Gail S. \& Brager Richard J. de Dear (1998) Thermal adaptation in the built environment: a literature review, Energy and Buildings, Vol. 27, 1/1998, p. 83-96, ISSN 0378-7788.

[6] Gligor, V. (2004) Luminous Environment and Productivity at Workplaces. Thesis. Espoo: Helsinki University of Technology.

[7] Gołębski, R. (2016) Parametric programming of CNC machine tools. MATEC Web Conf. Vol. 94,10 p. DOI:org/10.1051/matecconf/20179407004.

[8] Hendl, J., (2009): Overview of Statistical Methods. Analysis and meta-analysis of data. 3rd edition. Praha: Portal, 734 p. ISBN 978-80-262-0200-4.

[9] Humphreys, M. \& Nicol, F. (2007). Self-assessed productivity and the office environment: Monthly surveys in five European countries. ASHRAE Transactions. 113. 606-616.

[10] Ismail, A.R.; Rani, M.R.A.; Makhbul, Z.K.M.; Sopian,K. \& Deros, B.M.(2009)Thermal Comfort Assess-ment and Optimization of Environmental Factors by Using Taguchi Method, American Journal of Applied Sciences 6 (9): pp. 1731-1741, ISSN 1546-9239.

[11] Jirak, Z., et al., (2012) New Approach to assessing thermal humidity conditions in workplaces. In: Practice of Medicine. 64, 2012, No. 1, p. 23-31. ISSN 0032-6291.

[12] Kralikova, R. \& Wessely, E. (2016). Lighting Quality, Productivity and Human Health, Proceedings of the 27th DAAAM International Symposium, pp.0059-0065, DAAAM International, ISBN 978-3-902734-08-2, Vienna, DOI: $10.2507 / 27$ th.daaam.proceedings.009.

[13] Kralikova, R.; Pinosova, M. \& Hricova, B. (2016) Lighting Quality and its Effects on Productivity and Human Healts. In: Interdisciplinarity in Theory and Practice. No. 10 (2016), p. 8-12. - ISSN 2344-2409.

[14] Rezankova, H., (2011): Analysis of data from questionnaire surveys. Praha: Professional Publisching, 217 pp. ISBN 978-80-7431-062-1.

[15] Valea, P. \& Strajescu, E. (2017). Thermal Regime Aspects when Grinding Rubber Rolls for Paper Industry, Proceedings of the 28th DAAAM International Symposium, pp.0867-0874, , Published by DAAAM International, ISSN 1726-9679, Vienna, DOI: 10.2507/28th.daaam.proceedings.121.

[16] Yang, Rui-Liang; Liu, Lei \& Zhou, Yi-De (2015): Predicted Thermal Sensation Index for the Hot Environment in the Spinning Workshop. Mathematical problems in engineering.

[17] Fang, L.; Wyon, D.P.; Clausen, G. \& Fanger, P.O. (2004) Impact of indoor air temperature and humidity in an office on perceived air quality, SBS symptoms and performance. Indoor Air Journal 14(Suppl 7) pp.74-81.

[18] https://indoor.lbl.gov/sites/default/files/lbnl-60946.pdf Accessed on: 2017-06- 13

[19] EN 12464-1, Light and lighting - Lighting at work places - Part I: Indoor Work Places, European Standard.

[20] ISO 7730:2005 Ergonomics of the thermal environment -- Analytical determination and interpretation of thermal comfort using calculation of the PMV and PPD indices and local thermal comfort criteria.

[21] Decree of Ministry of Health of SR no. 99/2016 Coll. on health protection against heat and cold load at work.

[22] Decree of Ministry of Health of Slovak Republic no. 541/2007 Coll. on lighting requirements at work.

[23] https://rucore.libraries.rutgers.edu/rutgers-lib/36225/PDF/1/play/ 